\title{
Determinants of short- and long-term survival from colorectal cancer in very elderly patients
}

\author{
Juliette Sheridan ${ }^{a, *}$, Paul Walsh ${ }^{b}$, David Kevans ${ }^{a}$, Therese Cooney ${ }^{a}$, Shane O'Hanlon ${ }^{a}$, \\ Blathnaid Nolan ${ }^{a}$, Anne White ${ }^{a}$, Edel McDermott ${ }^{a}$, Kieran Sheahan ${ }^{a}$, Diarmuid O'Shea ${ }^{a}$, \\ John Hyland ${ }^{a}$, Diarmuid O'Donoghue ${ }^{a}$, Jacintha O'Sullivan ${ }^{c}$, Hugh Mulcahy $^{a}$, Glen Doherty ${ }^{a}$ \\ ${ }^{a}$ Centre for Colorectal Disease, St Vincent's University Hospital, University College Dublin, Elm Park, Dublin 4, Ireland \\ ${ }^{b}$ National Cancer Registry of Ireland, Kinsale Road, Cork, Ireland \\ ${ }^{\mathrm{C}}$ Department of Surgery, Institute of Molecular Medicine, Trinity Centre for Health Science, St. James's Hospital, Dublin 8, Ireland
}

\section{A R T I C L E I N F O}

Article history:

Received 2 November 2012

Received in revised form

13 March 2014

Accepted 28 April 2014

Keywords:

Colorectal cancer

Relative survival

Elderly

Ageing

Oxidative damage

Lipid peroxidation

\begin{abstract}
A B S T R A C T
Purpose: Over 5100 colorectal cancers (CRCs) are diagnosed in the United Kingdom in 85 years and older age group per year but little is known of cancer progression in this group. We assessed clinical, pathological and molecular features of CRC with early and late mortality in such patients.

Methods: Data were analysed in relation to early mortality and long-term survival in 90 consecutive patients with CRC aged 85 years or older in a single hospital.

Results: Patients not undergoing operation, those with an ASA score of III or greater and those with advanced tumour stage were more likely to die within 30 days. Regression analysis showed that 30 day mortality was independently related to failure to undergo resection (odds ratio (O.R.), 10.0; 95\% confidence interval [C.I.], 1.7-58.2; $\mathrm{p}=0.01$ ) and an ASA score of III or greater (O.R. 13.0; 95\% C.I., 1.4-12.6; $\mathrm{p}=0.03$ ). All cause three and five year survival were $47 \%$ and $23 \%$ respectively for patients who are alive 30 days after diagnosis. Three and five year relative survivals were $64 \%$ and $54 \%$, respectively. Long-term outcome was independently related to tumour stage (relative risk [R.R.], 2; 95\% C.I., 1.3-3.1; $p=0.001$ ), presence of co-morbid diseases (R.R., 2.8; 95\% C.I., 1.3-6.0; $p=0.007$ ) and lipid peroxidation status (R.R., 2.9; 95\% C.I., 1.1-7.5; $\mathrm{p}=0.025$ ).

Conclusions: An active multidisciplinary approach to the care of patients with CRC at the upper extreme of life is reasonable. It also seems sensible to individualise care based upon the extent of disease at diagnosis and the presence of co-morbid conditions. Further studies to examine the role of lipid peroxidation are warranted.
\end{abstract}

(c) 2014 Elsevier Ltd. All rights reserved.

\section{Introduction}

The age 85 years and older United Kingdom population increased from 875,000 in 1991 to 1.3 million in 2006 and this population is projected to increase to 3.1 million by 2032. ${ }^{1}$ These trends are mirrored by European statistics. Life expectancy is rising in the Western World and the average survival for 85 year-old males and females in the United Kingdom is now 5.8 and 6.6 years respectively and for 85 year-old Irish males and females it is 5.2 and 6.3 years. $^{2}$ Ageing is a major risk factor for colorectal cancer and United Kingdom incidence rates per 100,000 in men rise from 24

\footnotetext{
* Corresponding author. Tel.: +353 1221 4711; fax: +353 2214177.

E-mail address: Juliettedoody@gmail.com (J. Sheridan).
}

http://dx.doi.org/10.1016/j.jgo.2014.04.005

1879-4068/@ 2014 Elsevier Ltd. All rights reserved. 
cases per year at 45 years to 257 per year at 65 years and to 499 per year at 85 years $^{3}$ with over 5100 CRC currently being diagnosed in the United Kingdom in 85 years and older age group per year.

CRC is a model of a life-threatening but potentially curable disease and very elderly patients are interesting from both a clinical and scientific perspective. From a clinical viewpoint, care strategies are frequently based on trials from which older patients have been specifically excluded. ${ }^{4-6}$ Furthermore, elderly patients have, in many studies, failed to receive effective treatments based on the unfounded assumption that cancer is relatively benign in this age group, reluctance on the part of the primary provider to refer to a specialist centre, reluctance on the part of the patient, ${ }^{7}$ fear of possible toxicity, and that intensive therapy has little impact on the quality or quantity of remaining life. ${ }^{8-11}$ Since 2000, the recruitment of older patients into chemotherapy clinical trials has increased ${ }^{12}$ however there are no specific guidelines to direct diagnostic and therapeutic interventions in very elderly patients. The treatment of those at the upper extreme of life often presents significant clinical dilemmas. Considerable health care resources are expended on this disease and to improve CRC survival in the elderly, a critical reappraisal is needed of costs and benefits of treatments, and better selection of patients who can benefit from available therapies is warranted.

As suggested by Gundrum et al., if current trends continue into $2030,25 \%$ of cancer deaths may be in the over 85 years old age group, making it the most vulnerable group. ${ }^{13}$ Thus it is imperative that we conduct biomarker studies to study this cohort of patients and assess the disease similarities and differences in the disease processes versus their younger counterparts.

From a scientific perspective, the specific phenotypic and genotypic characteristics of cancer in very elderly patients are poorly understood. Ageing is generally thought to be associated with accumulation of damage in DNA, proteins and lipids and is also characterised by an increase in intracellular oxidative stress coupled with the production of free radicals. ${ }^{14}$ This oxidative stress may be a predisposing factor for a number of age related disorders including atherosclerosis, chronic inflammatory disorders and cancer. ${ }^{15,16}$ Oxidative stress results in the accumulation of a promutagenic lesion, 8-dihydro-2'-deoxyguanine (8-oxo-dG), possibly related to defective DNA repair mechanisms. ${ }^{17}$ Studies have demonstrated an increase of 8-oxodG levels with age from muscle DNA ${ }^{18}$ and leucocyte DNA ${ }^{19}$ from two cohorts of healthy individuals. Noren et al. showed serum levels of 8-oxodG increase with age in a cohort of middle aged women. ${ }^{20}$ Our group has previously demonstrated that nuclear oxidative damage (8-oxo-dG) is associated with poor survival in CRC across the age spectrum. ${ }^{21}$

Oxidative stress is also associated with lipid peroxidation and the formation of cytotoxic aldehydes including 4hydroxy-2-nonenal (4-HNE), a mutagen that is thought to play a role in carcinogenesis. ${ }^{22}$ High levels of 4-HNE is known to have an inhibitory effect on DNA repair and can impair p53 protein function through inhibition of thioredoxin reductase, a protein that governs normal p53 conformation and function $^{23-25} 4$-HNE is considered to be the most toxic product of lipid peroxidation. 4-HNE has been implicated in the tissue damage associated with ageing and other pathological states such as cancer, Alzheimer's, diabetes, cardiovascular and inflammatory complications. ${ }^{26}$

The variable prognosis of CRC in elderly patients is also of scientific interest as it may allow translational researchers to focus on identifying environmental, patient, tumour and therapeutic factors that might be modified to improve outcomes in the very elderly.

Prior clinical studies have compared survival between very elderly and younger patients with colorectal cancer and showed higher rates of right sided tumours and females in the very elderly. ${ }^{27}$ Post-operative pulmonary complications have been shown to be higher in the elderly ${ }^{28}$ however long term relative survival rates were similar when compared to younger patients. Studies have determined that surgical treatment should not be withheld for chronological age only. ${ }^{27-29}$ However, there has been little focus on those clinical, pathological or molecular features of colorectal cancer that might affect mortality at the upper extremity of life, or on potential mortality interactions between cancer and other diseases in this age group. We assessed such variables in 85 year old and older patients with CRC to identify those associated with early mortality and eventual clinical progression.

\section{Methods}

\subsection{Patient population}

We studied 90 consecutive patients aged 85 years or older (mean age 87.7 years, range 85.0-93.9) diagnosed with CRC in a single university teaching hospital between 1984 and 2005 (Table 1). All patients with colorectal cancer, are empirically treated according to an accelerated perioperative care package $\mathrm{e}^{30}$ that includes preoperative carbohydrate loading, avoidance of bowel preparation, early postoperative mobilisation and

\begin{tabular}{|c|c|}
\hline Variable & $\mathrm{N}=90$ \\
\hline \multicolumn{2}{|l|}{ Gender } \\
\hline Male & $31(24 \%)$ \\
\hline Female & $59(66 \%)$ \\
\hline \multicolumn{2}{|l|}{ Surgery } \\
\hline No & $8(9 \%)$ \\
\hline Yes & 82 (91\%) \\
\hline \multicolumn{2}{|c|}{ Primary tumour resection } \\
\hline No & $4(44 \%)$ \\
\hline Yes & $5(56 \%)$ \\
\hline \multicolumn{2}{|l|}{ Tumour stage } \\
\hline Stage I & $8(9 \%)$ \\
\hline Stage II & $38(42 \%)$ \\
\hline Stage III & 15 (17\%) \\
\hline Stage IV & 29 (32\%) \\
\hline \multicolumn{2}{|l|}{ Chemotherapy } \\
\hline No & 90 (100\%) \\
\hline Yes & $0(0 \%)$ \\
\hline \multicolumn{2}{|l|}{ Radiotherapy } \\
\hline No & 85 (94\%) \\
\hline Yes & $5(6 \%)$ \\
\hline
\end{tabular}


initiation of feeding, minimal use of drains, nasogastric tubes and opiates and maximum use of laparoscopic surgery, and endotherapy (which appears to be safe and effective in the elderly $)^{31}$ where indicated. In addition, these patients are assessed at a multidisciplinary team conference where treatment options are discussed and perioperative care is planned. Clinical and pathological data were retrieved from a prospective computerised database containing details on all patients with CRC. Furthermore, we retrieved and reviewed charts for all patients to confirm database details. Patients were followed-up to 2008 or until death, using data from out-patient clinic visits, primary care physicians and death certificates held by the National Cancer Registry, Ireland.

We used the American Society of Anesthesiologists (ASA) score to assess physical status at the time of surgery, or at diagnosis for those not undergoing surgery. We also calculated a co-morbidity score based on the presence or absence of specific disease states previously found to be associated with long-term outcome in colorectal cancer. ${ }^{32}$ Diseases included congestive heart failure, chronic obstructive pulmonary disease, diabetes mellitus, atrial fibrillation, cerebrovascular disease, dementia, chronic renal failure, peripheral vascular disease, liver disease, hip fracture, paralysis and venous thromboembolism. Finally, we calculated a functional score for each elderly patient based on the presence of impaired mobility, urinary or faecal incontinence or dependence on others to perform activities of daily living.

We retrieved formalin fixed paraffin embedded tumour specimens for 62 patients and constructed tissue microarrays using previously described methods. ${ }^{21}$ Immunohistochemistry was performed to assess expression of the mismatch repair proteins hMLH1 and MSH2, and nuclear and mitochondrial 8-oxo-dG levels were assessed as previously described by us. ${ }^{21,33}$ In addition, we assessed the levels of nuclear and cytoplasmic 4-HNE (Genox Corp, Baltimore, MD) in 62 elderly patients using the same immunohistochemistry protocol. Two independent observers assessed all 8-oxo-dG and 4-HNE staining in a blinded fashion for cellular localisation, percent positivity and intensity (Fig. 1). Approval for this study was obtained from the St Vincent's University Hospital Ethics Committee.

\subsection{Statistical Analysis}

Continuous data are presented as medians and interquartile ranges and were assessed using the Mann-Whitney U-test. Differences between proportions were assessed using the Chi-square test or Fisher's exact test and multivariate analyses using binary logistic regression analysis. Distributions of 8-oxo-dG and 4-HNE staining were divided around the median value where it is possible in order to develop usable groups to determine the effect of staining on survival in patients aged 85 years and older. The resulting groups contained different numbers of patients, but were as close to equal as it was possible to achieve. Kaplan-Meier survival curves were constructed with overall (all cause) survival or relative survival as end-points. Survival differences were assessed using the logrank test or Cox's proportional hazards model as appropriate using the Statistical Package for the Social Sciences (SPSS, Chicago, IL). Two sided p-values less than 0.05 were considered significant in all analyses.
Overall survival was defined as survival from the point of diagnosis of CRC. Relative survival was defined as the ratio of the proportion of observed cancer survivors to the proportion of expected survivors in the general population, adjusting for gender, age, and date at which the age was coded. Estimates of relative survival were calculated using the Ederer II method. ${ }^{34}$ This approach compares observed with expected survival at successive follow-up intervals to calculate interval-specific relative survival, then derives cumulative relative survival as the product of successive interval-specific relative survival estimates. Generalised linear modelling of relative survival was performed using Stata version 9.0 (StataCorp, Texas), applying standard generalised linear models to the excess hazard experienced by patients in comparison to the general population. ${ }^{35}$

\section{Results}

Twenty-seven patients (30\%) had rectal cancer, 25 (28\%) had left sided colonic cancer and 38 (42\%) had right sided disease. Eighty-two (91\%) underwent operation and 77 (86\%) primary tumour resection. Five patients $(6 \%)$ received radiotherapy but no patient received chemotherapy. Nine elderly patients (10\%) died within 30 days of diagnosis or surgery, 15 (17\%) within 60 days and 17 (19\%) within 90 days. Factors associated with 30 day mortality are shown in Table 2 . Patients who did not undergo operation, those with an ASA score of III or greater and those with advanced tumour stage (stage IV) at diagnosis were more likely to die within 30 days. Regression analysis showed that 30 day mortality in elderly patients was independently related to no resection performed (odds ratio (O.R.), 10.0; 95\% confidence interval [C.I.], 1.7-58.2; $\mathrm{p}=0.01$ ) and an ASA score of III or greater (O.R. 13.0; 95\% C.I., 1.4-123.6; $p=0.03$ ).

Subsequent overall three year and five year survivals were $47 \%$ and $23 \%$ respectively for the 81 patients 85 years and older who were alive 30 days after diagnosis or surgery. Three and five year relative survivals were $64 \%$ and $54 \%$, respectively. Long-term overall survival was most strongly related to tumour stage, but the presence of significant co-morbidity and patient gender were also associated with an eventual outcome (Table 3, Fig. 2). Neither microsatellite instability status nor 8-oxo-dG staining was associated with the outcome, but the small number with epithelial nuclear and stromal cytoplasmic 4-HNE staining tended to have a poor prognosis. Regression analysis identified only the tumour stage (relative risk [R.R.], 2.0; 95\% C.I., 1.3-3.1; $p=0.001$ ), the presence of unrelated co-morbid diseases (R.R., 2.8; 95\% C.I., $1.3-6 ; p=0.007$ ) and stromal cytoplasmic 4-HNE staining (R.R., 2.9; $95 \%$ C.I., $1.1-7.5 ; \mathrm{p}=0.025)$ to be independently associated with long-term outcome (Table 4).

\section{Discussion}

The age 85 and older population is rapidly rising in the Western World. As a consequence, the growing burden of social and health expenditure of cancer in the elderly is and will become a major challenge that health care systems 

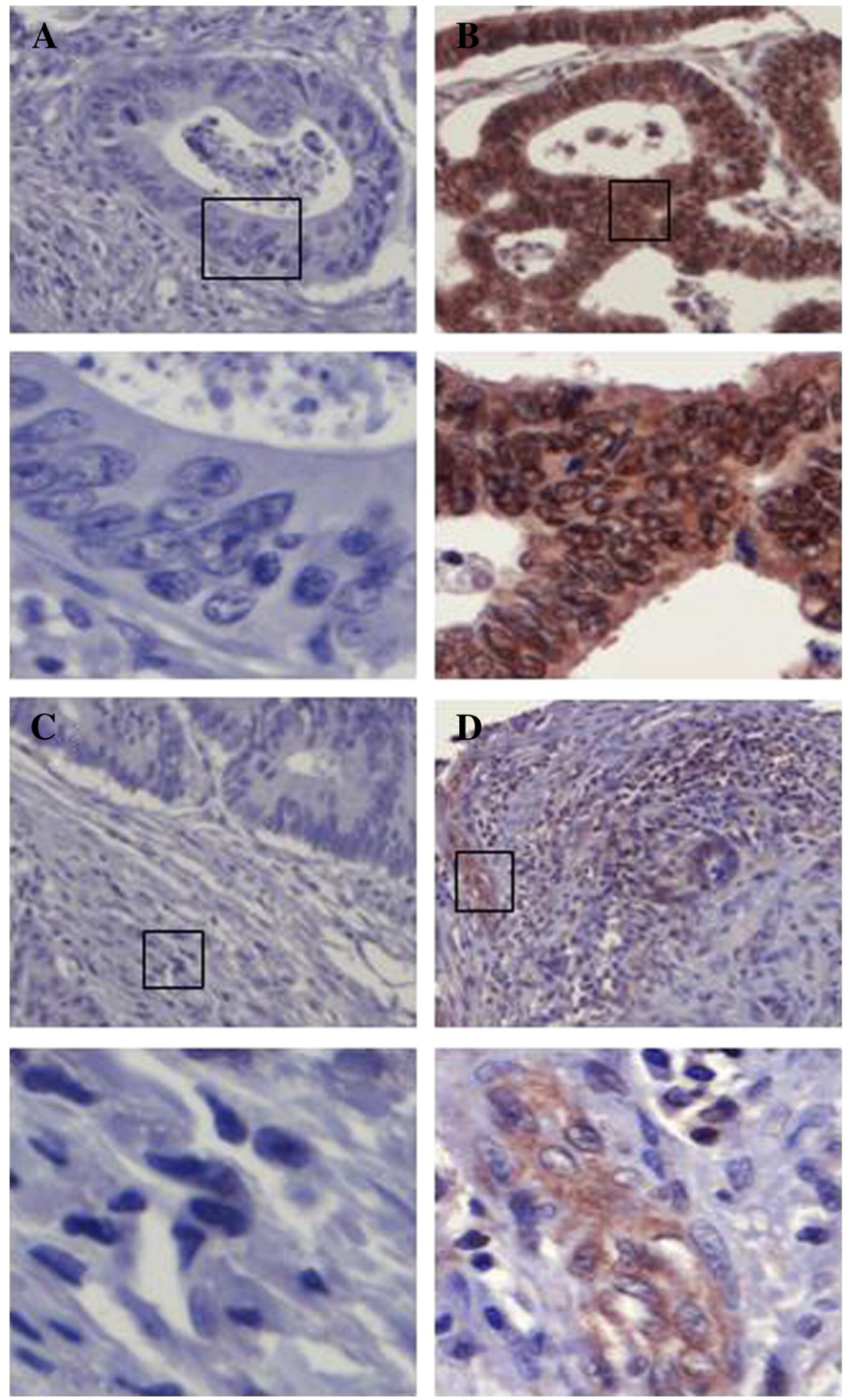

Fig. 1 - Representative immunohistochemical images of colorectal tumour tissue with the absence (panel A) and presence (panel B) of epithelial mitochondrial (cytoplasmic) 8-oxo-dG staining (at 10× and 60× magnifications). Nuclear 8-oxo-dG staining is also seen in panel B. Panels C and D show the absence and presence of stromal cytoplasmic 4HNE staining respectively (at $10 \times$ and $60 \times$ magnifications).

of many countries will have to cope with. A lack of comprehensive observational data on cancer in this patient cohort allied to their frequent exclusion from clinical trials leaves clinicians with a weak evidence base to guide decisions. Considerable health care resources are expended on this disease, and judicious alterations in care patterns might result in significant outcome benefits for patients and economic benefits for health care providers. ${ }^{36}$
Ten percent of patients aged 85 years and older died within 30 days of surgery or diagnosis. Those who did not undergo tumour resection and those with a high ASA score had the highest mortality. The ASA score was not designed to facilitate decision-making regarding surgery, nor would it be feasible to do so in clinical practice. Seven patients with an ASA score of III or more (24\%) died within 30 days, however 22 such patients (76\%) survived and their ASA score had no 
Table 2-Factors associated with 30 day mortality following diagnosis in 90 patients with colorectal cancer age 85 years and older.

Variable

\section{Dead at}

30 days

$(\mathrm{n}=9)$

Alive at

30 days

$(\mathrm{n}=81)$

\begin{tabular}{|c|c|c|c|}
\hline $\begin{array}{l}\text { Age (year) } \\
\text { (median [I.Q. range]) }\end{array}$ & $87.4(86.0-89.0)$ & $87.0(85.9-89.2)$ & $0.50^{\mathrm{a}}$ \\
\hline \multicolumn{4}{|l|}{ Gender } \\
\hline Male & $3(33 \%)$ & $28(35 \%)$ & \multirow[t]{2}{*}{$1.0^{\mathrm{b}}$} \\
\hline Female & $6(67 \%)$ & $53(65 \%)$ & \\
\hline \multicolumn{4}{|c|}{ Primary tumour resection } \\
\hline No & $4(44 \%)$ & $9(11 \%)$ & \multirow[t]{2}{*}{$0.02^{\mathrm{b}}$} \\
\hline Yes & $5(56 \%)$ & 72 (89\%) & \\
\hline \multicolumn{4}{|l|}{ Tumour stage } \\
\hline Stage I & 0 & $8(10 \%)$ & \multirow[t]{4}{*}{$0.003^{\circ}$} \\
\hline Stage II & $1(11 \%)$ & $36(46 \%)$ & \\
\hline Stage III & $1(11 \%)$ & $14(17 \%)$ & \\
\hline Stage IV & $7(78 \%)$ & $22(27 \%)$ & \\
\hline \multicolumn{4}{|l|}{ ASA score ${ }^{d}$} \\
\hline ASA I-II & $1(13 \%)$ & $48(62 \%)$ & \multirow[t]{2}{*}{$0.009^{\mathrm{b}}$} \\
\hline ASA III-V & $7(8 \%)$ & $29(38 \%)$ & \\
\hline \multicolumn{4}{|l|}{ Co-morbidity scores ${ }^{e}$} \\
\hline Score $=0$ & $2(25 \%)$ & $37(47 \%)$ & \multirow[t]{2}{*}{$0.29^{b}$} \\
\hline Score $\geq 1$ & $6(75 \%)$ & $42(53 \%)$ & \\
\hline \multicolumn{4}{|c|}{ Functional disability score ${ }^{f}$} \\
\hline Score $=0$ & $3(33 \%)$ & $46(58 \%)$ & \multirow[t]{2}{*}{$0.18^{\mathrm{b}}$} \\
\hline Score $\geq 1$ & $6(66 \%)$ & $33(42 \%)$ & \\
\hline
\end{tabular}

Because of rounding, percentages do not always total 100 .

a Mann-Whitney U-test.

b Fisher's exact test.

c Chi square test for trend.

d ASA score was not documented in 5 cases.

e Co-morbidity score was unavailable for three patients.

${ }^{\mathrm{f}}$ Functional disability score was unavailable for two patients.

influence on long-term outcome. The increased postoperative mortality in patients with a high ASA score suggests that further emphasis should be placed on maximising performance status after treatment options and possible outcomes have been discussed with patients and their family.

Our study showed females exhibiting a survival advantage. Previous studies have demonstrated a gender difference in survival with younger females exhibiting better survival rates partially explained by the favourable effect of endogenous female sex hormones. ${ }^{37,38}$ However these studies showed an opposite pattern in older female patients who exhibited lower survival rates. A recent study demonstrated a survival advantage in women up to the age of $64^{39}$; however, to our knowledge this is the first study to show a difference in survival between the sexes in the very elderly.

Multimorbidity is highly prevalent in the elderly population and has been shown to be associated with reduced survival in CRC in previous studies. ${ }^{32,40}$ This study re-iterated the impact of the presence of significant co-morbidity has on survival outcome, a co-morbidity score greater than one was independently associated with poor survival. It is likely that multi-morbidity affects survival outcome on several levels. Firstly, the presence of co-morbid conditions has a negative association with the receipt of standard cancer treatment. ${ }^{41}$ However it is likely that multimorbidity could affect the
Table 3-Clinical, pathological and molecular factors associated with long-term survival in 81 patients with colorectal cancer age $\mathbf{8 5}$ years and older who were alive 30 days after diagnosis.

\begin{tabular}{|c|c|c|c|}
\hline Variable & Number & $\begin{array}{c}\text { Three year } \\
\text { survival }\end{array}$ & $p$ value \\
\hline \multicolumn{4}{|l|}{ Gender } \\
\hline Male & 28 & $34 \%$ & \multirow[t]{2}{*}{$0.04^{\mathrm{a}}$} \\
\hline Female & 53 & $53 \%$ & \\
\hline \multicolumn{4}{|l|}{ ASA score ${ }^{b}$} \\
\hline ASA I-II & 48 & $46 \%$ & \multirow[t]{2}{*}{$0.70^{\mathrm{a}}$} \\
\hline ASA III-V & 29 & $50 \%$ & \\
\hline \multicolumn{4}{|l|}{ Co-morbidity score ${ }^{b}$} \\
\hline Score $=0$ & 37 & $63 \%$ & \multirow{2}{*}{$0.002^{\mathrm{a}}$} \\
\hline Score $\geq 1$ & 42 & $35 \%$ & \\
\hline \multicolumn{4}{|l|}{ Functional disability ${ }^{\mathrm{b}}$} \\
\hline Score $=0$ & 46 & $52 \%$ & \multirow[t]{2}{*}{$0.71^{\mathrm{a}}$} \\
\hline Score $\geq 1$ & 33 & $43 \%$ & \\
\hline \multicolumn{4}{|l|}{ Tumour stage } \\
\hline Stage I & 8 & $50 \%$ & \multirow[t]{4}{*}{$0.0001^{\mathrm{a}}$} \\
\hline Stage II & 37 & $69 \%$ & \\
\hline Stage III & 14 & $32 \%$ & \\
\hline Stage IV & 22 & $21 \%$ & \\
\hline \multicolumn{4}{|c|}{ Microsatellite instability status } \\
\hline Stable & 7 & $43 \%$ & \multirow[t]{2}{*}{$0.82^{\mathrm{a}}$} \\
\hline Unstable & 55 & $54 \%$ & \\
\hline \multicolumn{4}{|c|}{ Epithelial nuclear 8-oxo-dG ${ }^{\mathrm{c}}$} \\
\hline Low & 30 & $54 \%$ & \multirow{2}{*}{$0.15^{\mathrm{a}}$} \\
\hline High & 29 & $52 \%$ & \\
\hline \multicolumn{4}{|c|}{ Epithelial cytoplasmic 8-oxo- $\mathrm{dG}^{\mathrm{c}}$} \\
\hline Low & 27 & $49 \%$ & \multirow[t]{2}{*}{$0.92^{\mathrm{a}}$} \\
\hline High & 32 & $57 \%$ & \\
\hline \multicolumn{4}{|c|}{ Stromal nuclear 8-oxo-dG ${ }^{\mathrm{c}}$} \\
\hline Low & 24 & $60 \%$ & \multirow[t]{2}{*}{$0.98^{\mathrm{a}}$} \\
\hline High & 32 & $48 \%$ & \\
\hline \multicolumn{4}{|c|}{ Epithelial nuclear 4-HNE ${ }^{\mathrm{d}}$} \\
\hline Absent & 55 & $58 \%$ & \multirow[t]{2}{*}{$0.003^{\mathrm{a}}$} \\
\hline Present & 7 & $14 \%$ & \\
\hline \multicolumn{4}{|c|}{ Epithelial cytoplasmic 4-HNE ${ }^{\mathrm{c}}$} \\
\hline Low & 29 & $59 \%$ & \multirow[t]{2}{*}{$0.07^{\mathrm{a}}$} \\
\hline High & 33 & $47 \%$ & \\
\hline \multicolumn{4}{|c|}{ Stromal cytoplasmic $4-\mathrm{HNE}^{\mathrm{d}}$} \\
\hline Absent & 54 & $59 \%$ & \multirow[t]{2}{*}{$0.006^{\mathrm{a}}$} \\
\hline Present & 7 & $14 \%$ & \\
\hline 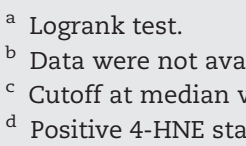 & $\begin{array}{l}\text { all cases. } \\
\text { nly } 7 \text { cases. }\end{array}$ & & \\
\hline
\end{tabular}

outcome independent of anti-cancer therapy, for example diabetes, renal failure, atherosclerosis and chronic obstructive pulmonary disease (COPD) are all are known to be associated with high levels of oxidative stress, could this higher level of oxidative stress be leading to a more aggressive tumour phenotype.

Surprisingly $21 \%$ of patients with stage IV cancer were alive at 3 years, despite not receiving chemotherapy. This highlights again the possibility that CRC in the very elderly cannot be deemed the same disease as in the younger counterparts. Furthermore, a recent study from The Netherlands showed that elderly patients with breast cancer have a higher risk not just for under-treatment but are also at risk for overtreatment and there exists a delicate balance between potential 

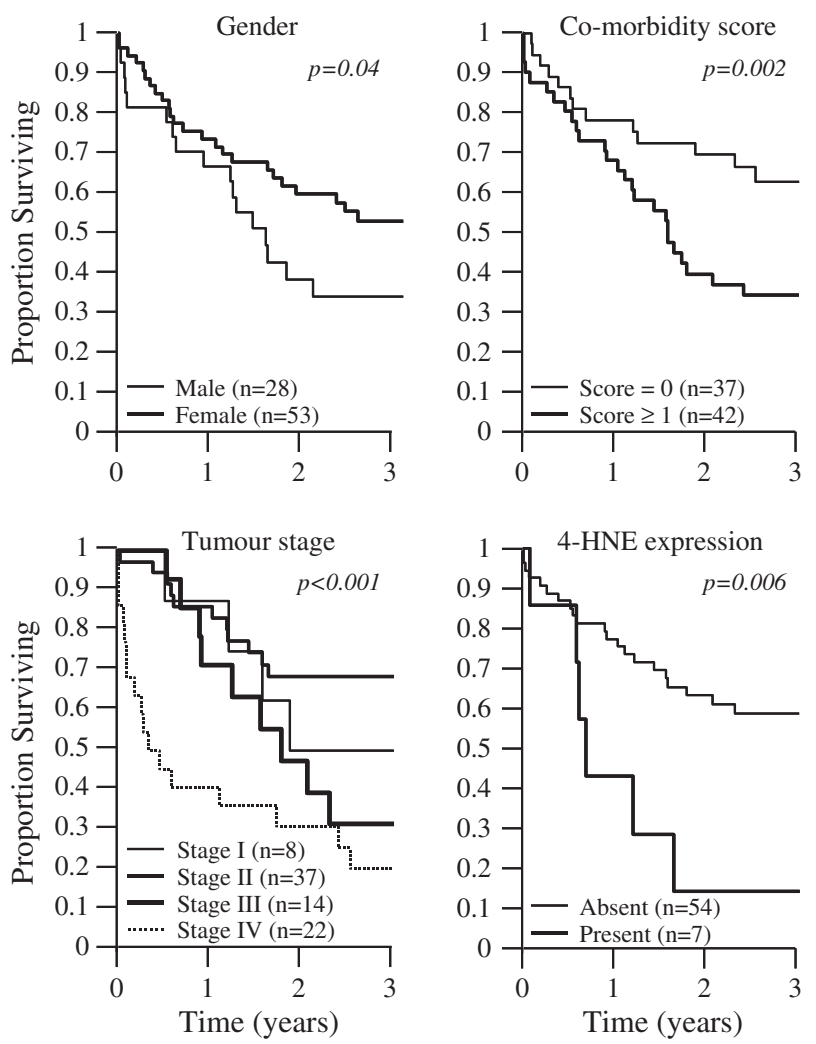

Fig. 2 - Survival of 81 patients with colorectal cancer, age 85 years and older, who were alive 30 days after diagnosis. 4-HNE expression refers to stromal cytoplasmic 4-HNE staining.

toxicities of treatment and survival gain. ${ }^{42}$ The number of elderly patients with CRC is increasing and will contribute to the strain on health resources. However, little is known about the optimal treatment for this age group. To improve CRC survival in the elderly, a critical reappraisal is needed for the cost and benefits of treatments, and a better selection of patients who can benefit from available therapies is warranted.

As part of our study, we assessed molecular factors that have been thought to be associated with ageing and which have also been implicated in cancer formation. The ageing process is associated with accumulation of mitochondrial DNA damage and increased mitochondrial oxidative stress. 8-oxo-dG staining was not associated with long-term outcome in these elderly patients in contrast to a previous study of a younger CRC group

Table 4 - Final Cox regression model identifying factors associated with overall long-term survival in $\mathbf{8 1}$ patients with CRC age 85 years and older who were alive 30 days after diagnosis.

\begin{tabular}{llll}
\multicolumn{1}{c}{ Variable } & Beta & $\begin{array}{c}\text { Odds ratio } \\
\text { (95\% C.I.) }\end{array}$ & p value \\
\hline Tumour stage & 0.7 & $2.0(1.3-3.1)$ & 0.001 \\
Co-morbidity score & 1.05 & $2.8(1.3-6.0)$ & 0.007 \\
Stromal cytoplasmic 4-HNE $^{\text {a }}$ & 1.08 & $2.9(1.1-7.5)$ & 0.025 \\
\hline
\end{tabular}

a Positive 4-HNE staining in only 7 cases. in which 8-oxo-dg staining was associated with poor outcome. ${ }^{21}$ If one considers the differences that have been noted in CRC presenting in the very young ( $<40$ years old) for example a higher prevalence of mucinous or poorly differentiated tumours including signet ring tumours which carry a poorer prognosis, ${ }^{43,44}$ it is not unreasonable to consider that CRC in the very elderly carries a different phenotype from the average CRC age group also, and that other factors may play a more important role in the pathogenesis and survival. The fact that the very elderly group have avoided cancer to this late age may represent a "healthier" lifestyle and it has been shown that both caloric restriction and moderate exercise lead to lower accumulation of both nuclear and mitochondrial 8-oxo-dG in both rat and human models. ${ }^{45,46} \mathrm{~A}$ recent study has suggested that diet, lifestyle, and genetic factors contribute to colorectal tumorigenesis through their influence on oxidative stress. It suggests that those with an inherited genetic profile placing them at higher risk for oxidative stress can reduce their colon and rectal cancer risk by diet and lifestyle factors. ${ }^{47}$

In contrast to nuclear and mitochondrial 8-oxo-dG levels, both epithelial and stromal 4-HNE staining strongly correlated with a poor outcome. Stromal cytoplasmic 4-HNE was associated with survival independent of both tumour stage and co-morbid conditions. 4-HNE is a by-product of lipid peroxidation which occurs as a consequence of oxidative stress in the mitochondria. During LPO, a variety of ROS and reactive nitrogen species (RNS) oxidize lipids leading to free radical chain reactions and subsequent formation of byproducts, like lipid radicals, hydrocarbons and aldehydes, ${ }^{48,24} .4$-HNE is an example of one such aldehyde. A number of recent studies have demonstrated not only an age-association of lipid peroxidation, but also an increase of lipid peroxidation in several age-related diseases, such as Alzheimer's ${ }^{49,50}$ and also in obesity and the metabolic syndrome ${ }^{51}$. These $\alpha, \beta$-unsaturated aldehydes are diffusible, can covalently modify proteins, and are known to form mutagenic DNA adducts ${ }^{52-54}$,. Amongst these, 4-HNE has been the most intensively studied and may additionally contribute to carcinogenesis by inhibiting DNA repair, ${ }^{25}$ inducing cyclooxygenase- 2 and modulating mitogen-activated protein kinase and nuclear factor $\kappa \mathrm{B}$ signalling. ${ }^{55-57}$ Wang et al. demonstrated that 4-HNE purified from enterococcus faecalis infected macrophages induced G2-M cell cycle arrest, leading to formation of $\mathrm{H} 2 \mathrm{AX}$ foci, and disrupted the mitotic spindle in both normal colonic epithelial and colon cancer cell lines. ${ }^{58}$ This study suggested the role of 4-HNE as a mediator of the bystander effects by the superoxide producing enterococcus faecalis. ${ }^{58}$ High levels of $4 \mathrm{HNE}$ have previously been noted in CRC tissue versus normal matched control ${ }^{59}$ however this is the first study that shows HNE levels to be associated with outcome in CRC in the elderly population. Our molecular results may point to subtle differences in the genesis of CRC at the upper extreme of life and further integration of clinical and laboratory research strands may provide additional insights into cancer initiation and progression in this very elderly patient group.

Our study is original insofar as it integrates clinical details, including pre-morbid disease states and functional status, with pathological results, molecular data, postoperative outcome and long-term survival in very elderly patients with colorectal cancer. A previous large population-based study, found that the decrease of cancer survival rates with increasing 
age at diagnosis was more marked in Europe and that elderly American patients had better prognosis than their European counterparts. This was felt to be secondary to earlier disease stage at diagnosis and more aggressive treatments regardless of age in the US. ${ }^{60}$ As a consequence of the relative survival rate results, we suggest that it is indeed reasonable to take an active multidisciplinary approach to the care of patients at the upper extreme of life and support a view that we should individualise care based upon the extent of disease at diagnosis, co-morbid conditions and the "biological" age rather than the "chronological" age.

\section{Disclosures and Conflict of Interest Statements}

No author has any conflict of interest or financial interest in this manuscript.

\section{Author Contributions}

Study Concepts: G. Doherty, H. Mulcahy, J. O’Sullivan, J. Sheridan, D. O'Shea

Study Design: G. Doherty, H. Mulcahy, J. O’Sullivan

Data Acquisition: P. Walsh, T. Cooney, S. O'Hanlon, B. Nolan, A. White, E. McDermott, K. Sheahan, J. Hyland, D. O'Donoghue Quality Control of Data and Algorithms: H. Mulcahy Data Analysis and Interpretation: D. Kevans, J. Sheridan, H. Mulcahy, J. O’Sullivan

Statistical Analysis: H. Mulcahy, J. Sheridan

Manuscript Preparation: G. Doherty, J. Sheridan, H. Mulcahy Manuscript Editing: J. O' Sullivan, H. Mulcahy, G. Doherty Manuscript Review: D. O’Donoghue, H. Mulcahy, J. O'Sullivan, G. Doherty

\section{Acknowledgement}

The authors would like to thank Dr. Peter Doran for his helpful comments during the preparation of this research.

\section{REF E R E N C E S}

1. http://www.statistics.gov.uk/downloads/theme_population/ Population-Trends-134.pdf.

2. WHO. http://www.who.int/whosis/database/life_tables/life_ tables.cfm.

3. http://info.cancerresearchuk.org/cancerstats/types/bowel/ incidence/uk-bowel-cancer-incidence-statistics\#By.

4. Hutchins LF, Unger JM, Crowley JJ, Coltman Jr CA, Albain KS. Underrepresentation of patients 65 years of age or older in cancer-treatment trials. N Engl J Med 1999;341(27): 2061-2067.

5. Trimble EL, Carter CL, Cain D, Freidlin B, Ungerleider RS, Friedman MA. Representation of older patients in cancer treatment trials. Cancer 1994;74(7 Suppl):2208-2214.

6. Talarico L, Chen G, Pazdur R. Enrollment of elderly patients in clinical trials for cancer drug registration: a 7-year experience by the US Food and Drug Administration. J Clin Oncol 2004;22(22):4626-4631.
7. Delva F, Marien E, Fonck M, Rainfray M, Demeaux JL, Moreaud $\mathrm{P}$, et al. Factors influencing general practitioners in the referral of elderly cancer patients. BMC Cancer 2011;11:5.

8. Damhuis RA, Wereldsma JC, Wiggers T. The influence of age on resection rates and postoperative mortality in 6457 patients with colorectal cancer. Int J Colorectal Dis 1996;11(1):45-48.

9. Lewis JH, Kilgore ML, Goldman DP, Trimble EL, Kaplan R, Montello MJ, et al. Participation of patients 65 years of age or older in cancer clinical trials. J Clin Oncol 2003;21(7):1383-1389.

10. Schrag D, Cramer LD, Bach PB, Begg CB. Age and adjuvant chemotherapy use after surgery for stage III colon cancer. J Natl Cancer Inst 2001;93(11):850-857.

11. Sundararajan V, Mitra N, Jacobson JS, Grann VR, Heitjan DF, Neugut AI. Survival associated with 5-fluorouracil-based adjuvant chemotherapy among elderly patients with node-positive colon cancer. Ann Intern Med 2002;136(5):349-357.

12. Unger JM, Coltman Jr CA, Crowley JJ, Hutchins LF, Martino S, Livingston RB, et al. Impact of the year 2000 Medicare policy change on older patient enrollment to cancer clinical trials. J Clin Oncol 2006;24(1):141-144.

13. Gundrum JD. Cancer in the oldest old in the Unites States, current statistics and projections. J Geriatr Oncol 2012;3(4):299.

14. Pacifici RE, Davies KJ. Protein, lipid and DNA repair systems in oxidative stress: the free-radical theory of aging revisited. Gerontology 1991;37(1-3):166-180.

15. Minuz P, Fava C, Cominacini L. Oxidative stress, antioxidants, and vascular damage. Br J Clin Pharmacol 2006;61(6):774-777.

16. Valko M, Izakovic M, Mazur M, Rhodes CJ, Telser J. Role of oxygen radicals in DNA damage and cancer incidence. Mol Cell Biochem 2004;266(1-2):37-56.

17. Loft S, Høgh Danielsen P, Mikkelsen L, Risom L, Forchhammer L, Møller P. Biomarkers of oxidative damage to DNA and repair. Biochem Soc Trans 2008;36(Pt 5):1071-1076.

18. Mecocci P, Fanó G, Fulle S, MacGarvey U, Shinobu L, Polidori $\mathrm{MC}$, et al. Age-dependent increases in oxidative damage to DNA, lipids, and proteins in human skeletal muscle. Free Radic Biol Med 1999;26(3-4):303-308.

19. Siomek A, Gackowski D, Rozalski R, Dziaman T, Szpila A, Guz J, et al. Higher leukocyte 8-oxo-7,8-dihydro-2"'-deoxyguanosine and lower plasma ascorbate in aging humans? Antioxid Redox Signal 2007;9(1):143-150.

20. Noren Hooten N, Ejiogu N, Zonderman AB, Evans MK. Association of oxidative DNA damage and C-reactive protein in women at risk for cardiovascular disease. Arterioscler Thromb Vasc Biol 2012;32(11):2776-2784.

21. Sheridan J, Wang LM, Tosetto M, Sheahan K, Hyland J, Fennelly D, et al. Nuclear oxidative damage correlates with poor survival in colorectal cancer. Br J Cancer 2009;100(2): 381-388.

22. Esterbauer H, Schaur RJ, Zollner H. Chemistry and biochemistry of 4-hydroxynonenal, malonaldehyde and related aldehydes. Free Radic Biol Med 1991;11(1):81-128.

23. Moos PJ, Edes K, Cassidy P, Massuda E, Fitzpatrick FA. Electrophilic prostaglandins and lipid aldehydes repress redox-sensitive transcription factors $\mathrm{p} 53$ and hypoxia-inducible factor by impairing the selenoprotein thioredoxin reductase. J Biol Chem 2003;278(2):745-750.

24. Petersen DR, Doorn JA. Reactions of 4-hydroxynonenal with proteins and cellular targets. Free Radic Biol Med 2004;37(7): 937-945.

25. Feng Z, Hu W, Tang MS. Trans-4-hydroxy-2-nonenal inhibits nucleotide excision repair in human cells: a possible mechanism for lipid peroxidation-induced carcinogenesis. Proc Natl Acad Sci U S A 2004;101(23):8598-8602.

26. Shoeb M, Ansari NH, Srivastava SK, Ramana KV. 4-hydroxynonenal in the pathogenesis and progression of human diseases. Curr Med Chem 2014;21(2):230-237.

27. Doherty G, Walsh P, Sheridan J, Kevans D, Keegan D, Nolan B, et al. Clinical and pathological factors associated with 
colorectal cancer at the upper extreme of life. J Am Geriatr Soc 2010;58(4):794-795.

28. Takeuchi K, Tsuzuki Y, Ando T, Sekihara M, Hara T, Kori T, et al. Should patients over 85 years old be operated on for colorectal cancer? J Clin Gastroenterol 2004;38(5):408-413.

29. Endreseth BH, Romundstad P, Myrvold HE, Bjerkeset T. Wibe A; Norwegian Rectal Cancer Group. Rectal cancer treatment of the elderly, Colorectal Dis 2006;8(6):471-479.

30. Nygren J, Hausel J, Kehlet H, Revhaug A, Lassen K, Dejong C, et al. A comparison in five European Centres of case mix, clinical management and outcomes following either conventional or fast-track perioperative care in colorectal surgery. Clin Nutr 2005;24(3):455-461.

31. Donnellan F, Cullen G, Cagney D, O'Halloran P, Harewood GC, Murray FE. Efficacy and safety of colonic stenting for malignant disease in the elderly. Int J Colorectal Dis 2010;25(6): 747-750.

32. Gross CP, Guo Z, McAvay GJ, Allore HG, Young M, Tinetti ME. Multimorbidity and survival in older persons with colorectal cancer. J Am Geriatr Soc 2006;54(12):1898-1904.

33. Fox EJ, Leahy DT, Geraghty R, Mulcahy HE, Fennelly D, Hyland JM, et al. Mutually exclusive promoter hypermethylation patterns of hMLH1 and 06-methylguanine DNA methyltransferase in colorectal cancer. J Mol Diagn 2006;8(1):68-75.

34. Dickman PW, Sloggett A, Hills M, Hakulinen T. Regression models for relative survival. Stat Med 2004;23(1):51-64.

35. Dickman PW, Adami HO. Interpreting trends in cancer patient survival. J Intern Med 2006;260(2):103-117.

36. Lang K, Lines LM, Lee DW, Korn JR, Earle CC, Menzin J. Lifetime and treatment-phase costs associated with colorectal cancer: evidence from SEER-Medicare data. Clin Gastroenterol Hepatol 2009;7(2):198-204.

37. Hendifar A, Yang D, Lenz F, Lurje G, Pohl A, Lenz C, et al. Gender disparities in metastatic colorectal cancer survival. Clin Cancer Res 2009;15(20):6391-6397.

38. Koo JH, Jalaludin B, Wong SK, Kneebone A, Connor SJ, Leong RW. Improved survival in young women with colorectal cancer. Am J Gastroenterol 2008;103(6):1488-1495.

39. Majek O, Gondos A, Jansen L, Emrich K, Holleczek B, Katalinic A, et al. Sex differences in colorectal cancer survival: population-based analysis of 164,996 colorectal cancer patients in Germany. PLoS One 2013;8(7):e68077.

40. Lemmens VE, Janssen-Heijnen ML, Verheij CD, Houterman S, Repelaer van Driel OJ, Coebergh JW. Co-morbidity leads to altered treatment and worse survival of elderly patients with colorectal cancer. Br J Surg 2005;92(5):615-623.

41. Koroukian SM, Bakaki PM, Schluchter MD, Owusu C. Treatment and survival patterns in relation to multimorbidity in patients with locoregional breast and colorectal cancer. J Geriatr Oncol 2011;2(3):200-208.

42. Bastiaannet E, Portielje JE, van de Velde CJ, de Craen AJ, van der Velde S, Kuppen PJ, et al. Lack of survival gain for elderly women with breast cancer. Oncologist 2011;16(4):415-423.

43. D'Onofrio GM, Tan EG. Is colorectal carcinoma in the young a more deadly disease? Aust N Z J Surg 1985;55(6):537-540.
44. Adkins Jr RB, DeLozier JB, McKnight WG, Waterhouse G. Carcinoma of the colon in patients 35 years of age and younger. Am Surg 1987;53(3):141-145.

45. Hamilton ML, Van Remmen H, Drake JA, Yang H, Guo ZM. Does oxidative damage to DNA increase with age? Proc Natl Acad Sci U S A 2001;98(18):10469-10474.

46. Nakamoto H, et al. Regular exercise reduces 8-oxodG in the nuclear and mitochondrial DNA and modulates the DNA repair activity in the liver of old rats. Exp Gerontol 2007;42(4):287-295.

47. Slattery ML, et al. Oxidative balance and colon and rectal cancer: interaction of lifestyle factors and genes. Mutat Res 2012;734(1-2): 30-40, http://dx.doi.org/10.1016/j.mrfmmm.2012.04.002 [Epub 2012 Apr 15].

48. Niki E. Lipid peroxidation: physiological levels and dual biological effects. Free Radic Biol Med 2009;47(5):469-484.

49. Padurariu $\mathrm{M}$, et al. Changes of some oxidative stress markers in the serum of patients with mild cognitive impairment and Alzheimer's disease. Neurosci Lett 2010;469(1): 6-10.

50. Reed TT, et al. Proteomic identification of HNE-bound proteins in early Alzheimer disease: insights into the role of lipid peroxidation in the progression of AD. Brain Res 2009;1274: 66-76.

51. Mattson MP. Roles of the lipid peroxidation product 4-hydroxynonenal in obesity, the metabolic syndrome, and associated vascular and neurodegenerative disorders. Exp Gerontol 2009;44(10):625-633.

52. Chung FL, et al. Deoxyguanosine adducts of t-4-hydroxy-2-nonenal are endogenous DNA lesions in rodents and humans: detection and potential sources. Cancer Res 2000;60(6):1507-1511.

53. Uchida K. 4-Hydroxy-2-nonenal: a product and mediator of oxidative stress. Prog Lipid Res 2003;42(4):318-343.

54. Emerit I, et al. Superoxide-mediated clastogenesis and anticlastogenic effects of exogenous superoxide dismutase. Proc Natl Acad Sci U S A 1996;93(23):12799-12804.

55. Zarrouki B, et al. The lipid peroxidation end-product 4-HNE induces COX-2 expression through p38MAPK activation in 3 T3-L1 adipose cell. FEBS Lett 2007;581(13):2394-2400.

56. Liu W, et al. Distinct involvement of NF-kappaB and p38 mitogen-activated protein kinase pathways in serum deprivation-mediated stimulation of inducible nitric oxide synthase and its inhibition by 4-hydroxynonenal. J Cell Biochem 2001;83(2):271-280.

57. Sharma A, et al. 4-Hydroxynonenal induces p53-mediated apoptosis in retinal pigment epithelial cells. Arch Biochem Biophys 2008;480(2):85-94.

58. Wang $\mathrm{X}$, et al. 4-hydroxy-2-nonenal mediates genotoxicity and bystander effects caused by Enterococcus faecalis-infected macrophages. Gastroenterology 2012;142(3): 543-551.

59. Skrzydlewska E, et al. Lipid peroxidation and antioxidant status in colorectal cancer. World J Gastroenterol 2005;11(3):403-406.

60. Gatta G, et al. Toward a comparison of survival in American and European cancer patients. Cancer 2000;89(4):893-900. 